\title{
A RELAÇÃO RAIZ E ESTRUTURA SINTÁTICA NA SEMÂNTICA DA FORMAÇÃO DE PALAVRAS NO PORTUGUÊS BRASILEIRO E ESPANHOL
}

\section{THE RELATIONSHIP BETWEEN ROOT AND SYNTACTIC STRUCTURE IN THE SEMANTICS OF WORD FORMATION IN BRAZILIAN PORTUGUESE AND SPANISH}

\author{
Rafaela do Nascimento Melo Aquino \\ Universidade Federal do Rio de Janeiro \\ Rio de Janeiro, Brasil \\ Isabella Lopes Pederneira \\ Universidade Federal do Rio de Janeiro \\ Rio de Janeiro, Brasil \\ Miriam Lemle \\ Universidade Federal do Rio de Janeiro \\ Rio de Janeiro, Brasil
}

RESUMO: Este trabalho teve por objetivo observar se é possível palavras com múltiplas camadas morfológicas ganharem novos significados, tendo em vista os estudos sintáticos sobre a relação entre a derivação das palavras e seus significados possíveis. Seguindo a teoria Exoesqueletal (BORER, 2005, 2013, 2015a e 2015b), assumimos que palavras complexas podem receber significados novos em nível morfológico superior à primeira junção entre a raiz e um morfema categorizador. Neste trabalho, mostraremos que dados de línguas aparentadas, como o Português do Brasil (PB) e o Espanhol (Esp), podem apresentar diferentes formas de inserção do conteúdo conceitual em palavras cognatas complexas. Com este estudo podemos trazer à teoria um avanço na compreensão da interface entre a sintaxe e a semântica.

PALAVRAS-CHAVE: Teoria exo-esqueletal; Palavras cognatas; Composicionalidade e não-composicionalidade em palavras complexas.

ABSTRACT: This work aimed to observe if it is possible complex words receive new abstract concepts, in view of the syntactic studies about the relation between the derivation of words and their meanings. Following the Exo-skeletal theory, proposed by Borer (2005, 2013, 
2015a and 2015b), we assume that words with a multiple morphological layers can receive new meanings at any morphological level that will be emerge after the first merge between the root and a functional head. In this work, we will show that data from languages of the same family, such as Brazilian Portuguese (PB) and Spanish (Esp), may present different forms of insertion of conceptual content into complex cognate words. With this study we can bring to the theory an advance in the understanding of the interface between syntax and semantics.

KEYWORDS: Exo-skeletal model; Cognate words; Compositionality and non- compositionality in complex words. 


\section{INTRODUÇÃO}

Os estudos sintáticos sobre a relação entre derivações das palavras e seus significados possíveis tentam delimitar o nível sintático no qual os significados idiomáticos podem emergir. As propostas construcionistas da Gramática Gerativa apresentam uma nova abordagem para essa delimitação. As duas principais teorias construcionistas assumidas neste texto são a Morfologia Distribuída (DM), proposta por Halle e Marantz (1993); e o Modelo Exo-esqueletal (ME), proposto por Borer $(2004,2005,2013)$. Essas teorias têm hipóteses semelhantes no que diz respeito à responsabilidade do sistema computacional na criação de palavras e têm diferentes suposições sobre o limite sintático de novos significados em palavras complexas.

O objetivo deste trabalho foi observar se é possível, palavras com múltiplas camadas morfológicas (isto é, aquelas cuja a estrutura morfossintática ultrapassa a camada raiz + nó funcional categorizador) ganharem novos conteúdos conceptuais, ou seja, novos significados. Seguindo a teoria Exoesqueletal, assumimos que palavras complexas podem receber significados novos em qualquer nível morfológico superior a primeira junção entre a raiz e um nó funcional (nominalizador, verbalizador, adjetivador), desde que não haja uma projeção estendida verbal delimitadora.

Neste trabalho, mostraremos que dados de línguas aparentadas, como o Português do Brasil (PB) e o Espanhol (Esp), podem apresentar diferentes formas de inserção do conteúdo conceitual em palavras cognatas complexas. Os dados apresentados serão nomes cognatos derivados do par de verbos correr/correr e bater/batir. A análise dos dados foi feita a partir da análise morfossintática, observando se houve mudança de leitura semântica no decorrer da derivação.

\section{DISCUSSÃO TEÓRICA}

O desenvolvimento da Gramática Gerativa em suas vertentes construcionistas trouxe uma nova maneira de olhar e, consequentemente, de estudar as palavras. Nestas novas visões, isto é, Morfologia Distribuída e Modelo Exo-esqueletal, o sistema computacional é responsável não só pela formação de sintagmas e sentenças, mas também de palavras. Deste modo, processos sintáticos como juntar, mover, copiar etc. também são acionados na formação de palavras. Esta proposta se diferencia das propostas lexicalistas, pois, a assunção de um léxico como um local em que as palavras são formadas antes da sintaxe é abandonada. Na proposta da MD, o 'léxico' é expandido em três listas responsáveis pelas fases da derivação morfossintática. A primeira lista contém os Traços Morfossintáticos, ou seja, os elementos base das operações sintáticas: traços funcionais e raízes. A segunda lista contém os Itens de Vocabulário a serem inseridos nos nós funcionais criados pela sintaxe, e a terceira lista, Enciclopédia, contém os significados possíveis para a estrutura morfossintática gerada pela derivação. Observe na Figura 1, uma representação deste modelo: 
Figura 2 - Modelo de gramática da Morfologia Distribuída

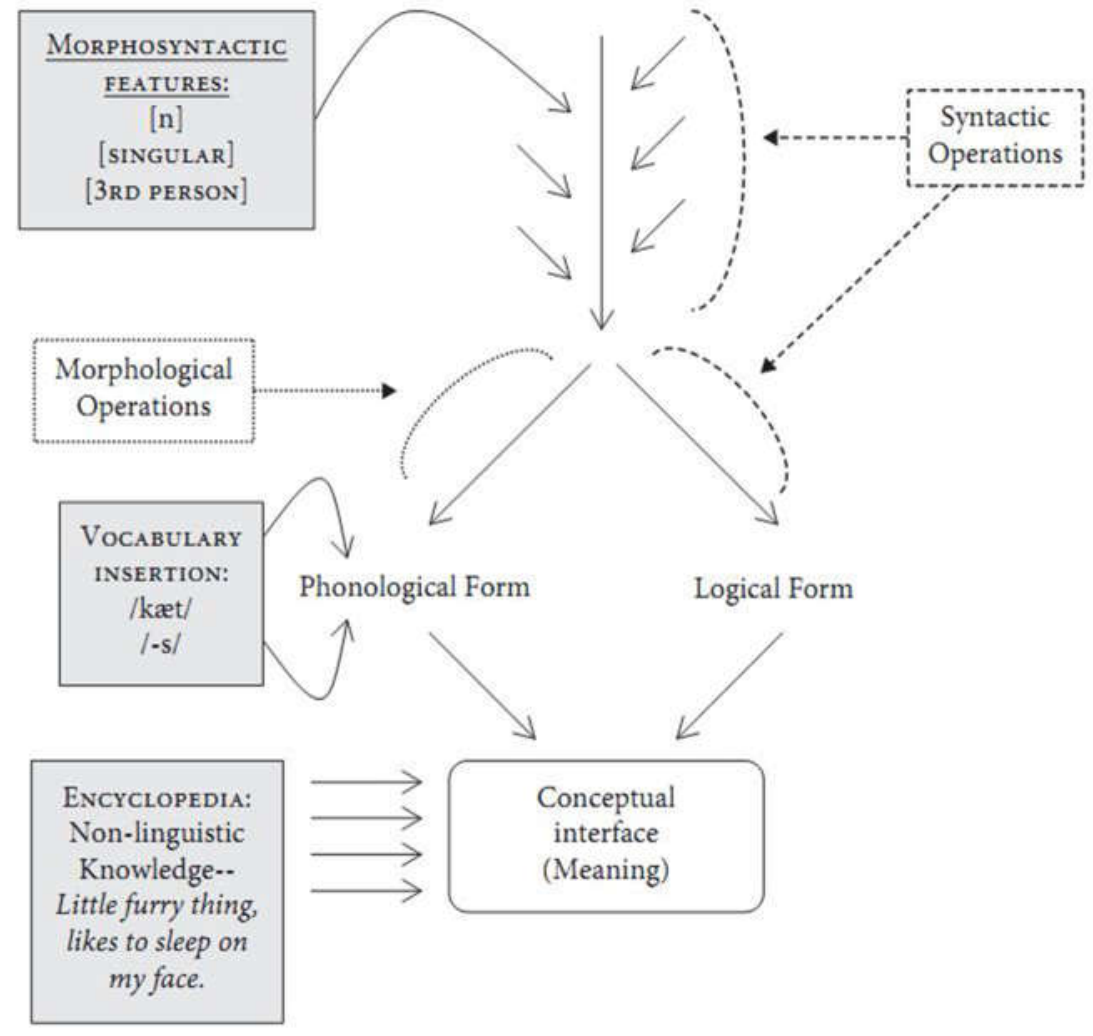

Fonte: SIDDIQI, 2009, p. 14.

Outro modelo aqui assumido é o proposto por Borer (2013c). Neste modelo, assim como na MD, é assumido que a sintaxe é o único sistema computacional, sendo responsável também pela formação de palavras. Este sistema trabalha com raízes e functores. As raízes (listemas) são índices fonológicos que não apresentam estrutura argumental, isto é, não projetam argumentos e não contêm conteúdo semântico. Esta assunção tem grande influência na nossa escolha pela comparação entre palavras cognatas em duas línguas aparentadas, pois, se as raízes não apresentam conteúdo semântico, as palavras que são formadas, etimologicamente, por uma mesma raiz em duas línguas da mesma família poderão apresentar significados totalmente distintos, seguindo caminhos de derivação morfológica muito diversos.

Os functores, por sua vez, são classificados em functores categoriais (Cfunctors) e functores semânticos (S-functors). Estes são, respectivamente, responsáveis por projetar e licenciar nós funcionais e lexicais. As estruturas sintáticas criadas a partir da junção destes elementos são enviadas para a forma lógica, a partir de spell-out. Após o spell-out, um mecanismo de busca enciclopédica é ativado e, assim, o conteúdo conceptual é combinado à estrutura criada. Observe abaixo o modelo acima descrito: 
Figura 3 - Modelo de gramática Exo-esqueletal

$\begin{aligned} & \text { COMPUTATIONAL SYSTEM } \\ & \text { (formal vocabulary, roots) }\end{aligned}$
$\downarrow$$\rightarrow$ spellout $\rightarrow$ en-searching $\rightarrow \begin{gathered}\text { Content (Conceptual } \\ \text { System) }\end{gathered}$

\section{Intentional Interface}

Fonte: BORER, 2014, p. 30.

As duas vertentes descritas brevemente acima também fazem assunções a respeito do nível sintático que restringe o surgimento de conceitos idiomáticos em palavras morfologicamente complexas. Por conceito idiomático entende-se conteúdo semântico que não provém da soma dos significados das peças morfológicas, como por exemplo, o significado ato covarde na palavra cachorrada no contexto Ele fez uma cachorrada comigo.

Para Marantz (2001) e Arad (2003), os conceitos enciclopédicos ou idiomáticos em palavras complexas podem surgir somente na primeira concatenação de um nó funcional $(n, v, a)$ a uma raiz acategorial. Deste modo, por consequência lógica, todas as camadas morfológicas posteriores terão leitura composicional. Observe o detalhamento desta hipótese nas figuras 3 e 4 a seguir:

Figura 4 - Primeiro ciclo de formação de palavras

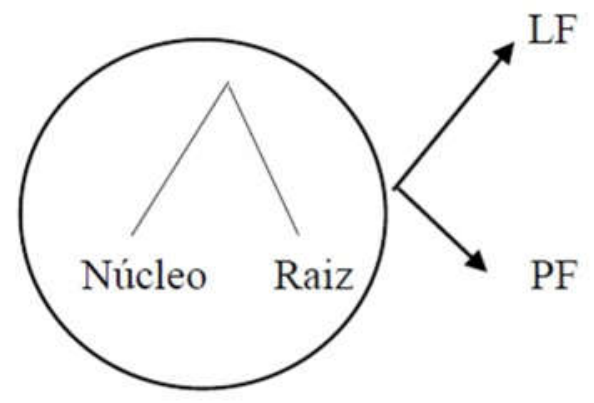

Leitura Arbitrária

Fonte: AQUINO, 2016, p. 22.

Figura 5 - Segundo ciclo de formação de palavras

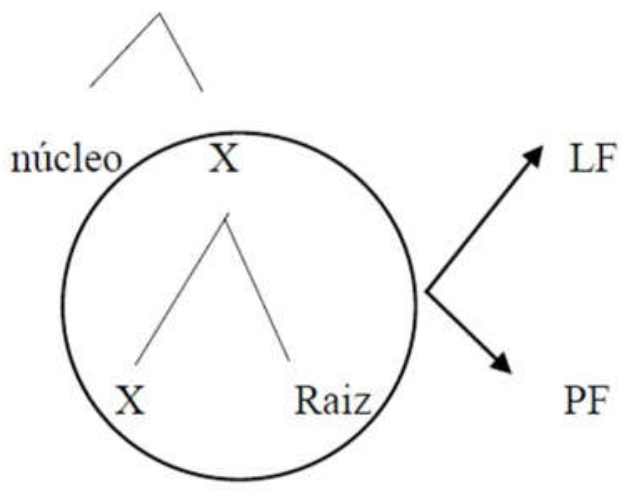

Leitura Composicional

Fonte: AQUINO, 2016, p. 22.

No entanto, esta assunção não dá conta de palavras como cachorrada (ato covarde), reacionário (conservador político) e refrigerante (bebida gasosa) em que o significado está longe de ser o resultado da combinação entre os 
significados das partes. Ou é possível dizer que a semântica de refrigerante (bebida gasosa) é composicional com a semântica de refrigerar?

Estes poucos exemplos já podem nos mostrar que esta proposta teórica da MD não é tão adequada para uma língua cujas palavras podem ter muitas camadas morfológicas como o PB. Para o nome cachorrada, por exemplo, não podemos assumir que a sua estrutura morfológica seja: [[ $\sqrt{ }$ cachorr $]$ ada $]_{n}$, uma vez que, em PB, o sufixo ada é concatenado a nomes, como por exemplo, martelo martelada, pedra - pedrada, papel - papelada, criança - criançada etc. Ao assumir que raízes não possuem categoria gramatical torna-se necessário lançar mão do processo sintático concatenar (merge) para categorizar uma raiz qualquer a partir de um nó funcional categorizador.

Este processo inicial já é a primeira camada em que, segundo Marantz (2001), o significado enciclopédico será encaixado. Este processo pode ser observado nos nomes base dos exemplos acima citados: cachorro, martelo, pedra etc. Seguindo este raciocínio, a derivação mais adequada para o termo cachorrada seria: [[[cachorr $\left.\left.]_{\Downarrow}\right]_{\mathrm{n}} \mathrm{ada}\right]_{\mathrm{n}}$, em que há uma primeira camada morfológica na qual a raiz $\sqrt{ }$ cachorr é nominalizada, tornando-se cachorro e, por conseguinte, o nome cachorro é derivado a partir do sufixo -ada, tornando-se cachorrada. Observe que este nome pode ter duas leituras. A primeira seria a leitura composicional, um grupo de cachorros, e a segunda seria idiomática, ato covarde.

A proposta teórica acima descrita, com poucos exemplos, já não se mostra tão adequada para uma análise de nomes derivados em PB. Deste modo, foi necessário lançar mão de outra teoria que desse suporte para casos de idiomatização em palavras morfologicamente complexas: a teoria Exo-esqueletal. Nesta teoria, os nomes deverbais são subdivididos em: nomes com estrutura argumental (AS-nominals) e nomes referenciais (R-nominals). Para os dois tipos de nome é assumido que o licenciamento de novos significados é dado pela sua estrutura sintática.

De acordo com Borer (2013c), os nomes do primeiro tipo apresentam as seguintes características: têm papéis relacionados a evento e precisam de argumentos, apresentam leitura eventiva, modificam agentes, seus sujeitos são argumentos, podem mudar a telicidade e, em espanhol, os sintagmas iniciados por por são seus argumentos. Para esses nomes é assumido que sua leitura será sempre composicional.

Os nomes do segundo tipo, por sua vez, não têm papéis relacionados a eventos, não necessitam de complementos, leitura eventiva não é necessária, não modificam agentes, os sujeitos são possessivos, não controlam argumentos, não podem ter mudança de telicidade e, em espanhol, selecionam sintagmas iniciados por de. No que diz respeito à leitura semântica desses nomes, é assumida a possibilidade de surgimento de conteúdo não-composicional. Algumas dessas características ficam claras nos exemplos a seguir com o nome plantação com leitura eventiva e plantação sem leitura eventiva.

a. A plantação de árvores pelos atletas olímpicos

b. O fogo consumiu toda a plantaçãode cana dos fazendeiros. 
Note que o nome plantação, significando espaço plantado de um terreno, representado em caixa alta, se estivesse na sentença em 1a), acarretaria em agramaticalidade, assim como o nome plantação, significando ato de plantar na sentença em 1b). Observe este fenômeno nos exemplos a seguir:

a. * A PLANTAÇÃO de árvores pelos atletas olímpicos

b. * O fogo consumiu toda a plantação de cana dos fazendeiros.

Diante destes exemplos, surge a pergunta: $O$ que faz estes nomes apresentarem comportamento sintático e semântico tão diferentes? A resposta, proposta por Borer (2013) e aqui assumida, é que a estrutura sintática desses nomes é diferente, influenciando no tipo de leitura que eles terão. Borer (2013) assume que os AS-nominals tenham uma projeção estendida verbal (Ex[V]) em sua estrutura sintática. Esta projeção estendida licenciará a leitura eventiva destes nomes e restringirá o mecanismo de busca enciclopédica (en-search), tendo como resultado a necessidade de leitura composicional. Observe a estrutura desses nomes na figura 5, na qual o retângulo em laranja significa 'limite final para busca enciclopédica'.

Figura 6 - Estrutura sintática dos AS-nominals

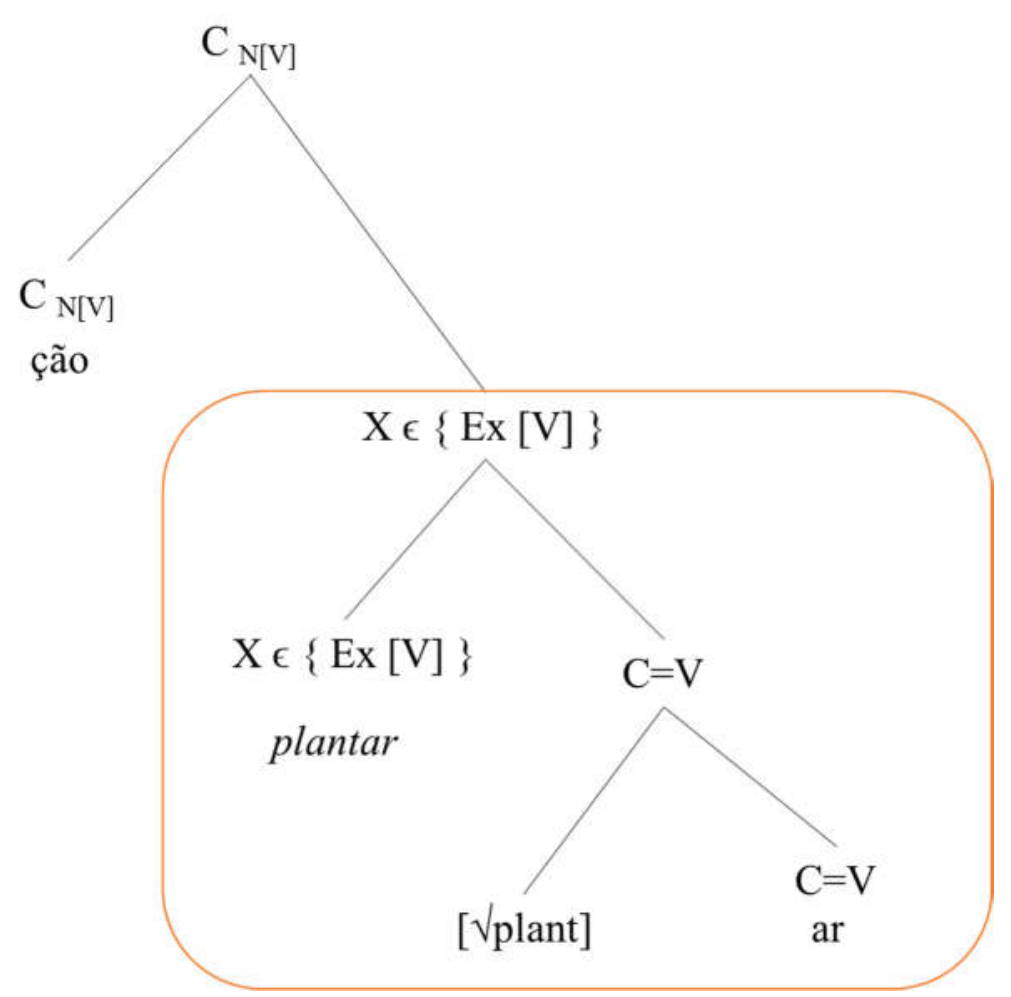

Fonte: Própria

Os R-nominals, por sua vez, não apresentam este nó sintático, tendo, portanto, a possibilidade de que o mecanismo de busca enciclopédica possa exercer a busca em qualquer nó sintático, fazendo com que o conteúdo não composicional possa ser encaixado em um nível elevado da derivação morfossintática. Observe esta estrutura na figura 6: 
Figura 7 - Estrutura sintática dos R-nominals

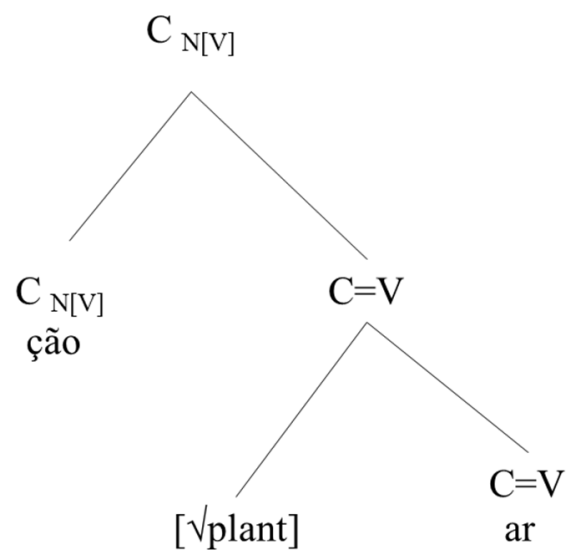

Fonte: Própria

Observe que, devido à falta de uma projeção estendida nos nomes referenciais, isto é, aqueles que não têm leitura eventiva, o conteúdo nãocomposicional pode ser encaixado em qualquer nível morfossintático. Logo, é assumido que somente R-nominals podem ter idiomaticidade semântica. Dito isso, observaremos agora exemplos da polissemia existente nos nomes complexos cognatos do português brasileiro e espanhol com as raízes $\sqrt{ }$ corr- e $\sqrt{ }$ bat-.

\section{ANÁLISE DE NOMES DEVERBAIS}

Nas propostas construcionistas da sintaxe, conforme vimos na seção anterior, uma grande responsabilidade é dada à estrutura sintática, ou seja, não é mais um item lexical com fonologia identificável que projeta a estrutura e determina seu significado concebido simplesmente em termos da 'arbitrariedade saussuriana'. Para a formação do significado de um item, a estrutura sintática em que ele se insere é crucial. Então, é possível considerar que as conexões sintáticosemânticas em que um determinado verbo apareça estejam disponíveis independentemente do item lexical.

O fenômeno da polissemia vem sendo estudado em linguística, porém, é nova a abordagem que relaciona o surgimento de novos significados e as estruturas sintáticas hierárquicas, provenientes da tradição gerativista (PEDERNEIRA, 2015, 2016), por exemplo, propõe estruturas eventivas para a polissemia de verbos leves no português brasileiro, baseando-se na teoria exoesqueletal. Daremos um novo passo nesse estudo, incorporando a polissemia de nomes em um estudo comparativo entre português brasileiro e espanhol.

\subsection{Nomes derivados da $\sqrt{ }$ corr-}

O português brasileiro e o espanhol apresentam os seguintes nomes cognatos formados a partir da $\sqrt{ }$ corr-: 
Tabela 1 - Nomes cognatos a partir de $\sqrt{ }$ corr-

\begin{tabular}{lll}
\hline \multicolumn{1}{c}{ Nome } & \multicolumn{1}{c}{ Português } & \multicolumn{1}{c}{ Espanhol } \\
\hline $\begin{array}{l}\text { Corredor } \\
{\left[[\text { corre }]_{\mathrm{v}} \mathrm{d} d o r\right]_{\mathrm{n}}}\end{array}$ & $\begin{array}{l}\text { Corredor brasileiro } \\
\text { Corredor da faculdade }\end{array}$ & $\begin{array}{l}\text { Corredor brasileño } \\
\text { Corredor de la casa }\end{array}$ \\
\hline $\begin{array}{l}\text { Corrente } \\
{\left[[\text { corre }]_{\mathrm{v}} \mathrm{nte}\right]_{\mathrm{n}}}\end{array}$ & $\begin{array}{l}\text { Corrente marítima } \\
\text { Corrente elétrica } \\
\text { Corrente da bicicleta }\end{array}$ & $\begin{array}{l}\text { Corriente maritima } \\
\text { Corriente electrica }\end{array}$ \\
\hline $\begin{array}{l}\text { Corrida } \\
{\left[\left[[\text { corri }]_{\mathrm{v}} \mathrm{d}\right]_{\mathrm{pp}} \mathrm{a}\right]_{\mathrm{n}}}\end{array}$ & Corrida de cem metros rasos & Corrida de toros \\
\hline $\begin{array}{l}\text { Correria } \\
{\left[[\text { corr }]_{\mathrm{v}} \mathrm{eria}\right]_{\mathrm{n}}}\end{array}$ & Correria no bairro & Correría de los guerrilleros (invasão) \\
\hline
\end{tabular}

Iniciaremos a análise a partir do nome corredor em PB e seu cognato em espanhol que, conforme representado brevemente na tabela acima, aparecem nos seguintes contextos sintáticos:

(3) a. O corredor brasileiro ganhou a maratona do Rio

b. O corredor da faculdade está limpo.

(4) a. El corredor brasileño gañó medalla de plata.

b. Nos sentamos en el corredor y tomamos limonada. (AQUINO, 2016, p. 61)

Note que este nome não poderia estar em sentenças como: * o CORREDOR brasileiro por $3 \mathrm{~km}$ em 2 horas ou * o CORREDOR da sala pelos pedreiros em três dias, pois, eles não têm leitura eventiva, não apresentam argumentos e não permitem modificação de telicidade, sendo, portanto, nomes referenciais (R-nominals). Conforme visto na seção 2, leituras idiomáticas podem emergir em nomes desse tipo.

Como podemos ver nos exemplos acima, as línguas se assemelham e o nome corredor e seu cognato espanhol apresentam duas leituras semânticas possíveis. A primeira delas é atleta que pratica corrida e a segunda passagem entre diferentes cômodos de um imóvel. No entanto, no que diz respeito à composicionalidade dessas leituras, nos exemplos (3a) e (4a), temos uma leitura composicional, enquanto, nos exemplos (3b) e (4b), a semântica é idiomática. Então, a estrutura de leitura seria: CORRE + dor, para corredor brasileiro e CORREDOR para corredor da faculdade. Ou seja, na segunda leitura, o conteúdo idiomático emerge na última camada morfológica $[\sqrt{ }$ corr $\left.\left.] \mathrm{e}]_{\mathrm{v}} \mathrm{d}\right]_{\mathrm{pp}} \mathrm{or}\right]_{\mathrm{n}}$.

$\mathrm{O}$ segundo termo a ser analisado será o nome corrente e seu cognato corriente, que aparecem nos seguintes contextos:

a. A corrente do mar está forte

b. Essa tomada está sem corrente.

c. A corrente da minha bicicleta saiu.

(6) a. Estas aguas són de fuertes corrientes.

b. Esta corriente electrica puede quemar las manos. 
A partir dos exemplos (5) e (6) já podemos ver que as línguas portuguesa e espanhola não se assemelham em todos os usos deste nome, pois o PB apresenta o uso em (5c) que não é encontrado com nome cognato em espanhol. Nas sentenças em (5a) e (6a), o nome corrente e seu cognato apresentam leitura de fluxo contínuo de água. Já em $5(\mathrm{~b})$ e $6(\mathrm{~b})$, a leitura é de fluxo contínuo de energia elétrica e, em (5c), na língua portuguesa, é de liame composto de elos metálicos. Em todos esses casos, os nomes não apresentam leitura eventiva, ou seja, são nomes referenciais, pois não poderiam estar em uma sentença como: * A CORRENTE da bicicleta pelo ciclista em 5 horas. Quanto ao nível sintático no qual a leitura semântica emerge nesses nomes, temos nos casos em (5a) e (5b), (6a) e (6b), a estrutura CORRE + nte e, no caso (5c), a estrutura CORRENTE.

Outro nome formado a partir da raiz de correr é o nome corrida. Este nome e seu cognato aparecem nos seguintes contextos:

a. O atleta queniano ganhou a corrida.

b. Vou dar uma corrida no parque.

Las corridas de toros són mui peligrosas.

Nos exemplos em (7), o nome significa, respectivamente, modalidade esportiva, sendo a leitura semântica encaixada no nível morfológico mais alto: CORRIDA, e ato de correr, cuja estrutura é CORRI + da. Já no exemplo em (8), o nome recebe a leitura de evento cultural e aparece somente no contexto 'de toros', neste caso, a leitura idiomática recai na palavra como um todo: CORRIDA. Note que uma sentença como: * A CORRIDA na praia pelos atletas por três horas é agramatical porque este nome não apresenta leitura eventiva, assim como, o exemplo em (7b), no qual o nome está encaixado em uma estrutura de verbo leve dar +- ada $^{1}$, em que a leitura de evento é dada pelo verbo leve dar. Logo, este é um nome referencial.

Por fim, temos o nome correria e seu cognato que aparecem nos seguintes contextos:

(9) a. O desmoronamento do prédio causou uma correria na cidade

b. Esta semana estou na correria.

(10) a. En su última correria los guerrilleros no respetaron nada

b. Lo acompañó em sus correrias por la ciudad

Podemos observar através dos exemplos que este nome apresenta entre as línguas significados completamente distintos. Em PB, nos exemplos (9a) e (9b), correria significa, respectivamente, pessoas correndo desordenadamente e ritmo acelerado da vida. Já em espanhol, nos exemplos (10a) e (10b) correria significa, respectivamente, invasão e andanças.

No que diz respeito ao tipo de nome deverbal, tanto em PB quanto em espanhol, o nome correria é um nome referencial, pois, conforme a

\footnotetext{
${ }^{1}$ Para saber mais sobre essa estrutura de verbo leve, confira Scher, 2006.
} 
agramaticalidade das sentenças * a correria pelas pessoas em uma hora ou * la correria por los invasores demonstra, este lexema não apresenta leitura eventiva, não possibilita modificação de telicidade e não apresenta argumento iniciado por por. Neste caso, as estruturas com as camadas nas quais as leituras idiomáticas emergem em cada caso serão, respectivamente, CORRE + ia, CORRERIA, CORRERÍA e CORRERÍA.

Note que nos dois últimos casos, embora o conteúdo idiomático apareça na última camada morfológica, o nome apresenta leituras diferentes que são listadas na enciclopédia e selecionadas a partir de uma estrutura sintática que as licencie, como, por exemplo, o ambiente sintático em que o segundo caso de correria, na sentença (10b), está contido. Neste contexto, o nome é licenciado pelo sintagma locativo iniciado por por.

\subsection{Nomes derivados de $\sqrt{ }$ bat-}

Uma das nominalizações possíveis para a base verbal bater é a partir da nominalização do particípio passado deste verbo não adjetivado: batida. Esta nominalização denota o resultado do evento de bater que, por sua vez, apresenta grande variabilidade semântica: colidir, investigar, roubar entre outras. Observe a seguir os exemplos com os usos deste nome nas línguas aqui estudadas:

(11) a. Mulher morre em batida de carro

b. Siga a batida da música

c. Como fazer uma batida de maracujá?

d. Hoje teve uma batida policial

(12) a. Batida policial contra los coches mal aparcados.

b. Yo acostumbro todas lãs mañanas hacer un batido de manzana

Note que, em português, nas sentenças em (11), batida denota, em cada exemplo, respectivamente, colisão, ritmo musical, bebida feita a partir da mistura de frutas com bebidas alcoólicas e investigação policial. Já nas sentenças em (12), o nome batida/o tem como conteúdo semântico: investigação policial e bebida feita a partir da mistura de frutas e leite. A comparação do uso deste item nominal entre as línguas portuguesa e espanhola revela uma grande falta de correspondência entre as escolhas lexicais destas línguas, ou seja, o aproveitamento semântico deste nome na língua portuguesa é maior que o da língua espanhola.

Em comparação com as leituras semânticas do verbo bater, o nome batida apresenta em português tanto leituras composicionais quanto leituras idiossincráticas, conforme os casos apresentados na Tabela 2. No primeiro caso desta tabela, a semântica do verbo bater (colidir) está na base do nome batida mencionadas na tabela abaixo: contato abrupto entre dois corpos sólidos, produção de ruído rítmico e bebida alcoólica feita agitando um container com cachaça e pedaços de fruta. O significado de investigar para o verbo bater (A 
polícia bateu toda a região) provém de uma metáfora e está na base do significado do nome batida, representado na quarta linha da tabela a seguir.

Tabela 2 - Comparação semântica entre o verbo bater e o nome batida em português

\begin{tabular}{llll}
\hline \multicolumn{1}{c}{ Base verbal } & \multicolumn{1}{c}{ Conteúdo } & Nome derivado & \multicolumn{1}{c}{ Conteúdo } \\
\hline bater o carro & COLIDIR & Batida & sem conteúdo novo listado \\
\hline bater a fruta & MISTURAR & Batida & BEBIDA ALCÓOLICA \\
\hline bater a área & INVESTIGAR & Batida & sem conteúdo novo listado \\
\hline
\end{tabular}

Quanto à língua espanhola, embora não tenha todas essas variedades de uso do nome batida, também apresenta ocorrências com conteúdo idiomático no nome quando comparado à semântica da base verbal batir, no caso de milkshake. Observe a tabela a seguir:

Tabela 3 - Comparação semântica entre o verbo batir e o nome batida em espanhol

\begin{tabular}{ccll}
\hline Base verbal & \multicolumn{1}{c}{ Conteúdo } & \multicolumn{1}{c}{ Nome derivado } & \multicolumn{1}{c}{ Conteúdo } \\
\hline Batir la zona & INVESTIGAR & Batida & sem conteúdo novo listado \\
\hline Batir la fruta & MISTURAR & Batido & MILKSHAKE \\
\hline
\end{tabular}

Há também em português e espanhol um nome construído a partir da concatenação do sufixo - or ao particípio passado do verbo bater. Esse sufixo tem por contribuição semântica a noção de agente ou instrumento, conforme os exemplos abaixo:

(13) a. Me passa o batedor de ovos

b. Ele é batedor de comboio presidencial

c. Taxista ajuda a prender um batedor de carteira

(14) a. Él es batidor de comboio presidencial

b. Pasame la batidora de huevos

Nestas sentenças, o nome significa, respectivamente, instrumento utilizado para bater ovos, policial ou soldado que vai à frente da caravana e ladrão. Apenas em (13a) e (13b), as línguas se assemelham no uso do item lexical. Para a sentença em (13c), a língua espanhola não apresenta uma construção idiomática com o nome cognato. Note que, em português, a construção batedor de carteira é gerada a partir da expressão idiomática bater carteira (roubar). No caso de batedor de comboio presidencial, temos no nome batedor o significado de abrir caminho, que está perdido no uso do verbo bater. Para melhor entendimento, observe a tabela 4 . 
Tabela 4 - Comparação semântica entre o verbo bater e o nome batedor em português

\begin{tabular}{llll}
\hline \multicolumn{1}{c}{ Base verbal } & Conteúdo & Nome derivado & Conteúdo \\
\hline bater ovos & COLIDIR & batedor (de ovos) & sem conteúdo novo listado \\
\hline bater carteira & ROUBAR & batedor (de carteira) & sem conteúdo novo listado \\
\hline
\end{tabular}

O espanhol, por sua vez, apresenta três concepções para o nome batidor, conforme representado na tabela abaixo. A primeira e a segunda são composicionais e a última tem conteúdo idiomático: um policial/soldado que abre caminho. Os dois últimos casos se distinguem pelo fato da seguinte sentença ser possível em espanhol: enviaron a un batidor para que se adelantara (enviaram a um explorador para que se adiantasse), isto é, o nome batidor desta sentença é composicional em relação a leitura semântica explorar do verbo batir em espanhol.

Tabela 5 - Comparação semântica entre o verbo batir e o nome batidor em espanhol

\begin{tabular}{lcll}
\hline \multicolumn{1}{c}{ Base verbal } & Conteúdo & Nome derivado & \multicolumn{1}{c}{ Conteúdo } \\
\hline Batir los huevos & MISTURAR & batidora & sem conteúdo novo listado \\
\hline Batir lo camino & EXPLORAR & Batidor & sem conteúdo novo listado \\
\hline $\begin{array}{l}\text { Batir lo } \\
\text { caminho }\end{array}$ & EXPLORAR & Batidor & $\begin{array}{l}\text { POLICIAL QUE ABRE } \\
\text { CAMINHO }\end{array}$ \\
\hline
\end{tabular}

É interessante notar que em português o nome batedor no caso de batedor de ovos denota, somente, instrumento utilizado para bater ovos, diferentemente da língua espanhola, na qual o nome batidora denota instrumento utilizado para bater. Essa curiosidade demonstra que uma palavra pode apresentar um aproveitamento semântico maior em uma língua, quando comparada a outra língua aparentada.

Uma terceira possibilidade de nome deverbal com a $\sqrt{ }$ bat- é a partir da junção do sufixo - mento à base verbal. Este sufixo contribui semanticamente com a noção de resultado de uma ação. Observe os exemplos que se seguem:

a. Como se mede o batimento cardíaco?

b. $\mathrm{O}$ batimento das asas do Beija-Flor é muito rápido.

(16) a. ¿Sabes calcular los latidos del corazón?

b. La frecuencia del batimiento de las alas del colibri es mas o menos de 70 a 80 veces por segundo (Google).

O nome batimento e seu correspondente espanhol batimiento, conforme mostrado nas sentenças acima, apresentam leituras composicionais. Neste caso, o verbo bater está denotando metaforicamente uma colisão. Em português, essa metáfora se estende a coração e a asas. Já em espanhol, somente o bater das asas é descrito pelo verbo e, consequentemente, pelo nome. Dito isto, ainda é válido notar a falta de correspondência lexical entre as línguas nas sentenças (15a) e (16a), na qual a língua espanhola se utiliza de um derivado composicional 
do verbo latir para representar a noção das batidas do coração, noção esta que, em português, é descrita a partir de bater. A Vbat- também é aproveitada no nome batente, formado a partir da concatenação do sufixo -nte à base verbal. Observe os exemplos a seguir:

(17) a. Eu preciso trocar o batente da porta.

b. Hoje eu pego no batente às seis da manhã.

(18) Aquella puerta estuvo golpeando el batiente toda la noche (Google).

Nas sentenças acima, em português, o nome apresenta as seguintes leituras semânticas: lugar onde a porta bate e trabalho. Ao comparar com a língua espanhola, constatamos a ausência da construção idiomática pegar no batente (trabalhar), na qual batente significa trabalho. Esta falta de semelhança entre as línguas é esperada em casos de expressões idiomáticas, embora existam algumas exceções. Em espanhol, apenas a leitura lugar onde a porta bate é descrita por esse nome. Em português, no exemplo (17a), emerge um conteúdo especial para a base verbal e nenhum novo conteúdo especial para o derivado, o que o torna composicional. Já em (17b), o conteúdo não-composicional TRABALHO emerge somente no item derivado batente como um todo. Em espanhol, por sua vez, o item batiente apresenta apenas a leitura composicional.

\section{CONSIDERAÇÕES FINAIS}

Este artigo propunha-se a analisar dois pares de verbos cognatos e os seus nomes derivados em português brasileiro e espanhol. As análises dos nomes deverbais foram feitas partindo da hipótese de que palavras complexas podem apresentar significados idiossincrásicos, deixando de ter relação semântica composicional com suas partes morfológicas. Conforme visto nas análises destas palavras na seção 3 , é possível compreender que a hipótese de que os conceitos vinculados às palavras podem ser modificados se aplica na maioria dos casos estudados. Observando palavra por palavra nota-se que a relação semântica composicional é muito produtiva, como se deve esperar. No entanto, uma mesma palavra complexa pode apresentar tanto leituras composicionais quanto idiomáticas. É importante notar que muitas das leituras apresentadas pelas palavras devem-se à variabilidade semântica dos verbos que estão na sua base, porém, ainda assim, conceitos novos são atribuídos nas palavras complexas idiomatizadas como um todo.

Este estudo nos mostra que a possibilidade de surgir conceitos novos em palavras complexas está presente nas línguas, porém cada língua se serve deste mecanismo em escalas diferentes. A comparação entre duas línguas aparentadas nos mostrou que nos pares de palavras complexas cognatas cada peça lexical de um dos pares pode se comportar de forma autônoma, confirmando que as raízes não apresentam conceito básico. Dito isso, a partir do estudo das relações semânticas entre a base verbal e a palavra derivada foi possível perceber que o 
significado pode estar presente: (i) somente na base verbal, sendo a palavra derivada semanticamente regular; (ii) somente na palavra complexa, confirmando que o surgimento de novos conteúdos conceptuais não são obrigatórios e são cíclicos e; (iii) tanto na base verbal quanto na palavra derivada, revelando a possibilidade de conteúdo novo em palavras morfologicamente complexas.

\section{REFERÊNCIAS}

AQUINO, Rafaela do Nascimento Melo. Encontros e desencontros semânticos em palavras cognatas das línguas portuguesa e espanhola. Dissertação de Mestrado. UFRJ, 2016.

ARAD, Maya. "Locality constraints on the interpretation of roots: the case of Hebrew denominal verbs". In: Natural Language \& Linguistic Theory. [S.l.: s.n.], 2003. v. 21 , p. $737-778$.

BORER, Hagit. "The Grammar Machine". In: ALEXIADOU A., E. A.; EVERAERT, M. (Ed.). The Unaccusativity Puzzle. Oxford: Oxford University Press, 2004.

2005.

. In Name Only. Structuring Sense. Oxford: Oxford University Press,

. Roots and Categories. Circle of Generative Grammar: University of the Basque Country, 2009. Handout. Disponível em: $<$ http://webspace.qmul.ac.uk/hborer/downloads/roots \and $\_$categoriesrevised.pdf> Acesso em 2 jun 2014

2013.

. Taking Form: Structuring Sense. Oxford: Oxford University Press,

. "Derived Nominals and the Domain of Content". In: Lingua, v. 141, p. $71-96$, Março 2014.

HALLE, Morris; MARANTZ, Alec. "Distributed Morphology and the Pieces of Inflection". In: The View from Building 20: Essays in Linguistics in Honor of Sylvain Bromberger. Cambridge, MA: MIT Press, 1993. p. 111- 176.

MARANTZ, Alec. Words. Handout, 2001. Disponível em: $<$ http://babel.ucsc.edu/ hank/mrg.readings/Marantzl_words.pdf $>$ Acesso em 4 abr 2014

PEDERNEIRA, Isabella Lopes. Implicações teóricas dos verbos leves para o estudo da estrutura argumental. Tese de Doutorado. UFRJ. 2015.

Implicações teóricas dos verbos leves para o estudo da estrutura argumental. ALFA. 2016. 
SCHER, Ana Paula. "Nominalizações em -ada em Construções com o Verbo Leve dar em Português Brasileiro". In: Letras de Hoje, Porto Alegre, v. 41, n. 1, p. 29-48, março 2006.

SIDDIQI, Daniel. Syntax within the Word: economy, allomorphy, and the argument selection in Distributed Morphology. Amsterdan: John Benjamins Publishing Company, 2009.

Rafaela do Nascimento Melo Aquino

LitteraMelo@gmail.com

Isabella Lopes Pederneira SPederneira@hotmail.com

Miriam Lemle MiriamLemle@gmail.com

Recebido em: 6 mar. 2018 Aceito em: 14 jun. 2018 Publicado em: 19 ago. 2018 